\title{
Public acceptance of energy technologies: The effects of labeling, time, and heterogeneity in a discrete choice experiment
}

\author{
Frank J. van Rijnsoever*, Allard van Mossel, Kevin P.F. Broecks \\ Innovation Studies, Copernicus Institute of Sustainable Development, Utrecht University, Heidelberglaan 2, 3584 CS, Utrecht, The Netherlands
}

\section{A R T I C L E I N F O}

\section{Article history:}

Received 24 June 2014

Received in revised form

28 December 2014

Accepted 8 February 2015

Available online 27 February 2015

Keywords:

Public acceptance

Preference dynamics

Discrete choice experiment

Labeling

Energy technologies

Socio-political acceptance

\begin{abstract}
A B S T R A C T
Public acceptance is crucial for successful implementation of energy technologies in society. However, studies that use the concept do so in diverse and often inconsistent ways. They also often limit themselves to specific technologies and do not account for the effects of labeling, time, and the heterogeneity of the general public, which may lead to a biased and incomplete understanding of public acceptance. This study first conceptualizes three forms of public acceptance: socio-political acceptance, market acceptance and community acceptance. It then relates the concept of socio-political acceptance to preference formation. Next, it uses two discrete choice experiments that were conducted in 2010 and 2012 to investigate these concerns. Our results show that public preferences for energy technologies are temporally stable, even in the face of exogenous shocks such as the Fukushima incident. Using mixed logit models, we further show that labeling has a profound influence on stated preferences. When technology labels are revealed, respondents favor renewable and natural gas technologies. When labels remain unobserved, nuclear energy and biomass take prominence. However, latent class models show that there are distinct classes of respondents, tied to specific socio-demographic characteristics that differ greatly in their sensitivity to labeling and in the temporal stability of their preferences. It follows that changes in public acceptance are not population-wide, but remain limited to specific sub-groups. We discuss the theoretical and policy implications of our findings and conclude that future studies and policy initiatives may overlook important insights if they disregard the effects of labels, time, and heterogeneity.
\end{abstract}

\section{Contents}

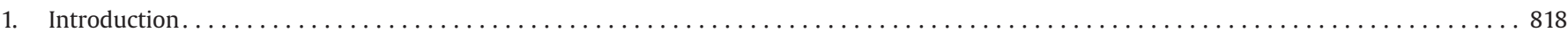

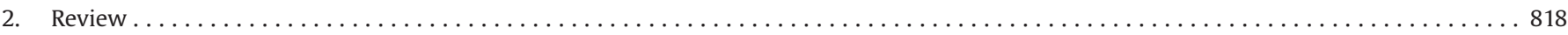

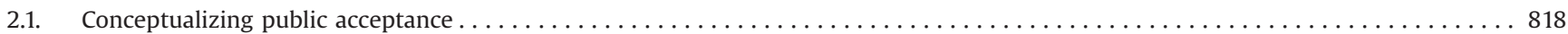

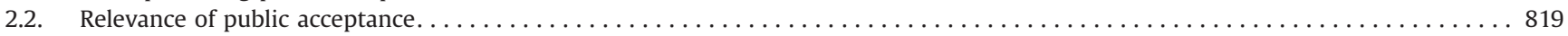

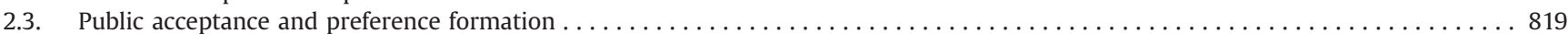

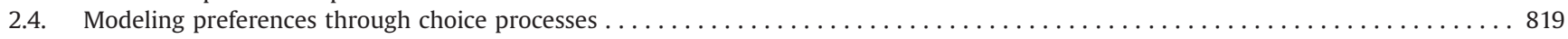

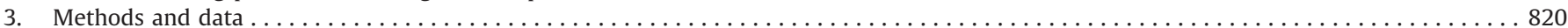

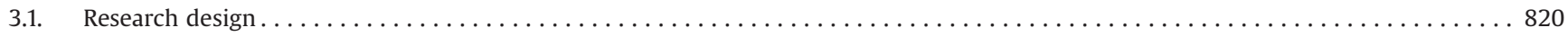

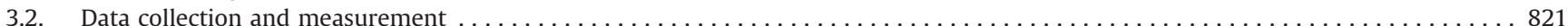

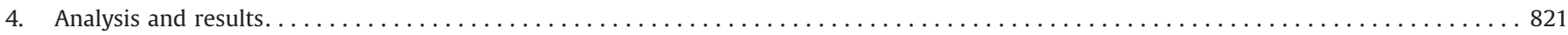

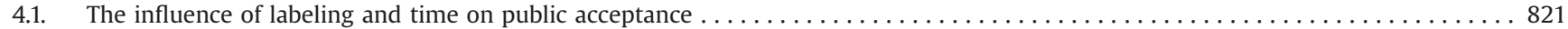

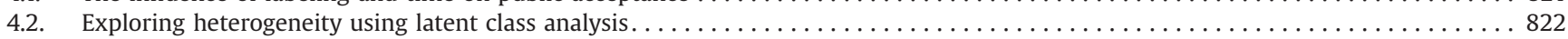

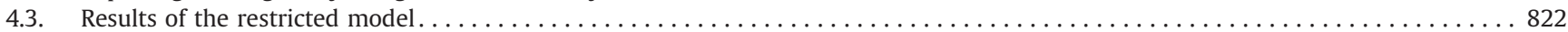

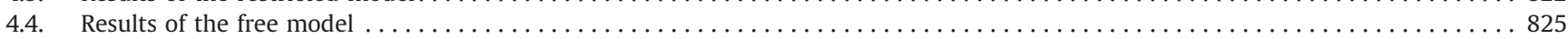

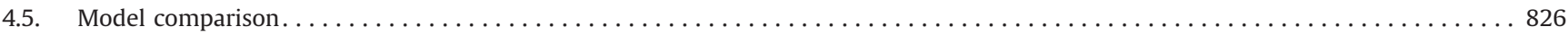

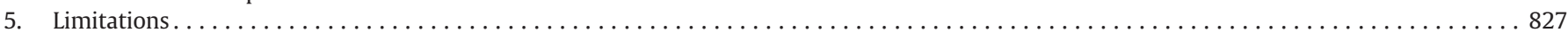

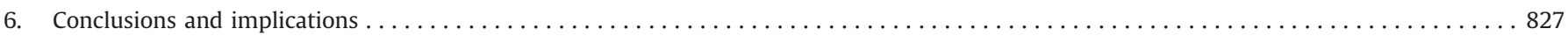

\footnotetext{
*Corresponding author. Tel.: +31302537484.

E-mail address: f.j.vanrijnsoever@uu.nl (F.J. van Rijnsoever).
} 


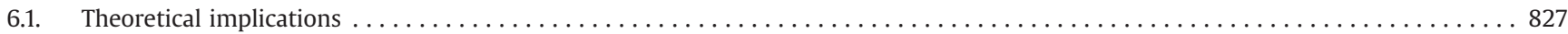

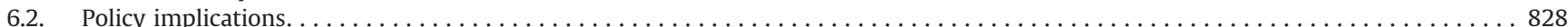

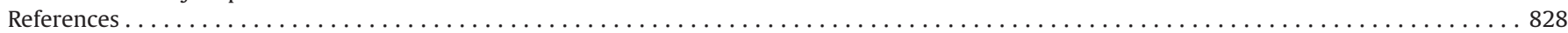

\section{Introduction}

Public acceptance is crucial for successful implementation of technologies in society. Energy technologies currently encounter significant public opposition in several countries. The German government, for example, shut down all national nuclear facilities after the 2011 Fukushima incident incited widespread public opposition. High public acceptance eases the implementation of technologies in society, but when acceptance is low, it hinders - or even halts - their implementation. Attaining renewable energy targets while accounting for public preferences is a substantial challenge to policy makers. The current Dutch policy framework for renewable energy, for example, is based on an agreement between a range of national and local stakeholders, such as ENGOs, unions and companies [1]. Increasing understanding of the determinants of public acceptance and preference can aid policy makers in making more informed decisions for renewable energy policies.

The public acceptance of energy technologies has received limited scientific attention, despite its influence on innovation success [2]. Most studies on the topic are limited to specific technologies, such as carbon capture and storage (CCS) [3,4], wind energy [5-7], biomass energy $[8,9]$, solar energy $[10,11]$, or nuclear energy $[12,13]$. However, future energy systems will likely consist of multiple energy technologies. A focus on one technology is also too narrow for a real understanding of public acceptance, because it leads to a bias resulting from myopic decision-making [14]. For reliable measurement of the public acceptance of a technology it is therefore important to compare it with available alternatives, as was done empirically by Bergmann et al. [12,14], Zoellner et al. [16], and in meta-studies that combine the results of public acceptance studies [17].

Several additional caveats remain unexplored when it comes to systematically understanding the public acceptance of energy technologies.

First, there is a lot of ambiguity surrounding public acceptance [18] due to its multidimensional nature [2]. To fully understand the role of public acceptance in energy innovation processes, studies need to specify clearly which aspect of public acceptance they are studying and why this aspect in particular is relevant to the issue at hand.

Second, research shows that individuals not only base their choice on a technology's observed attributes, but also infer other attributes from a label. Labels such as product names, technology names or brand names function as heuristic cues [19,20]. The label can invoke thoughts and feelings that do not necessarily match the observed attributes of a technology. For example, nuclear energy often invokes feelings of dread, which greatly influences its acceptance by the public [21,22].

Third, preferences for alternatives are often unstable over time $[14,23]$. Thoughts and feelings associated with a label can change under the influence of new information. For example, the incidents at Chernobyl and Fukushima may strengthen the negative associations of with the label "nuclear energy."

Fourth, by only presenting the average valuations of different alternatives, many public acceptance studies implicitly ignore the fact that the general public is heterogeneous-the opinions of individuals can vary substantially $[24,25]$. Understanding this heterogeneity facilitates segmented communication approaches. This can improve the acceptance of technologies among subclasses and, thereby, reduce controversy.
In this paper, we first review existing literature on public acceptance of (energy) technologies, preference formation and preference diffusion. Next, we expand upon the state-of-the-art by demonstrating how labeling and time affect acceptance of energy technologies among different classes of the public. We do this by analyzing two latent class choice models, using data from two discrete choice experiments conducted in 2010 and 2012.

\section{Review}

\subsection{Conceptualizing public acceptance}

It is often unclear what the concept of public acceptance entails, since it has a dual meaning. It variably refers to an attitude towards a technology or to a form of behavior that supports or resists the implementation of a technology. However, psychological models [26] point out that attitudes do not always incite the associated behavior. Negative attitudes, for example, do not always lead to protests. As such, there are different indicators of public acceptance that are not necessarily consistent [18].

We base our conceptualization of public acceptance on the roles that individuals can play in the different stages of an innovation process. Two different role types, citizens and consumers, shape the public acceptance of a new technology [27,28]. Citizens are usually only indirectly involved in the development and diffusion of novel technologies. They shape the innovation process by voicing their opinions or by displaying actions that support or resist a technology, both before and after market introduction. Consumers effectively play two direct roles; as adopters and as users [29]. Although consumers often combine these roles, this is not always the case. Consumers can, for example, donate or share a purchased good. Moreover, it should be noted that consumers can also be organizations. Following Van Rijnsoever and Oppewal [30], we take the view that adopters and users are relevant at different stages in the innovation process. Adopters play a role in the acceptance process once opportunities for direct interaction with the technology become available, such as test facilities, prototypes, or products and services that can be purchased. Users are those who use the technology or experience its consequences.

Based on these roles, we arrive at the three interdependent dimensions of public acceptance by Wustenhagen et al. [2]: sociopolitical acceptance, community acceptance, and market acceptance.

- Socio-political acceptance refers to the role of citizens. It is primarily manifested through general support for a technology or for policies that support its development. This component of acceptance is often gauged through opinion polls that represent the aggregated attitudes of citizens [31,32]. Socio-political acceptance further comprises the acceptance by key stakeholders and policy makers, who can employ various strategies to influence socio-political acceptance (see [33] for an overview). Prominent strategies are the voicing of opinions by societal groups or stakeholders in the media, seeking the help of political parties, or engaging in direct dialogue with developers. Socio-political acceptance can foster market and community acceptance by legitimizing policies for social site characterization [34] 
(community acceptance) or feed-in tariffs [35] (market acceptance), for example.

- Market acceptance refers to role of consumers as adopter. It is revealed primarily through the adoption process of technology. An adopter can be an individual, but can also be a firm or any other type of agent that is able to adopt the technology. Goods or services that attract sufficient market demand are most likely to be retained and to 'diffuse' through the population [36,37], while others are discarded ${ }^{1}$.

- Community acceptance refers to the role of consumers as voluntary or involuntary users of technology. It plays an important role in those cases where the adoption of an innovation affects large groups of agents such as, for example, the siting decisions for renewable energy installations. Local stakeholders, such as residents, local authorities and employees can object to projects even when sufficient socio-political or market acceptance have been secured. These situations are often attributed to the 'not in my backyard' (NIMBY) syndrome, although the underlying mechanism of this syndrome are poorly understood $[6,38,39]$.

In this paper we focus on socio-political acceptance as an aggregate of the individual attitudes of citizens.

\subsection{Relevance of public acceptance}

The influence socio-political acceptance on policy and the strength of its interdependencies with other dimensions of acceptance depend on factors such as the topic salience, characteristics of the decision maker, media appearance, the lobby power of other stakeholders, and possible upcoming elections [40,41]. Influence can manifest itself through changes in funding, regulations, or expected market demand. The importance of socio-political acceptance in innovation processes is expected to increase in the future for three reasons.

First, technological progress has greatly decreased the barriers to obtaining reliable information about public preferences. Technologies such as the Internet allow for fast and direct measurement of public opinion through large-scale surveys [42]. New media allow for instant dissemination of findings. In this manner public opinion serves as feedback to policy makers and political parties. Politicians use it as a tool in political debates and react to shifts in public opinion by changing their ideological positions [43]. Second, science is held increasingly accountable for its societal benefits [44-47]. Whenever innovations for renewable energy technologies require significant public funding, the opinion of the general public has to be taken into account in order to legitimize the innovation $[32,48]$. Lastly, community initiatives for renewable energy [34,49-51], have increased the agency of citizens in co-creating knowledge, innovation and technology. As a result, the voice of citizens in the development of renewable energy projects is increasing. For these reasons it is important to better understand the formation of public preferences.

\subsection{Public acceptance and preference formation}

In our conceptualization, acceptance implies that citizens prefer one state (e.g. the existing situation), over another (e.g. one in which a new energy technology has been implemented). It is important to understand how citizens form preferences on the basis of the information that they receive. Citizens rarely have

\footnotetext{
${ }^{1}$ A wider understanding of market acceptance also includes professional investors, and consumers or communities as investors [93]. However, we did not include this here, because this relates to how new technological varieties are created [94], not to public acceptance.
}

well-defined preferences for objects that they are not familiar or experienced with. Instead, they often 'construct' their preferences instantaneously and will "selectively use information that is part of the immediate task description, as well as information that is drawn selectively from memory, to construct a response on the spot" [11], p. 245. Constructed preferences can be based on highly selective use of information, avoidance of tradeoffs and involve limited reflection.

In psychology, dual processing $[52,53]$ models indicate that particular types of situations are more conducive to such limited, peripheral or heuristic processing. In these situations, rather than systematically processing all of the information that is available to them, agents rely on heuristics to simplify decision making, such as the expertise or likability of the source of the information [54] or the feelings (affect) generated by the information [22]. The preferences that they form in this way are unstable and more likely to change over time [52,53]. Heuristic cues, such as brands or labels [54], provide easy access to heuristics and distract from other information. Attaching labels to a description of an energy technology can therefore trigger feelings and thoughts that do not correspond with the description that is provided $[19,20]$.

Preferences for technologies are likely to vary between agents $[24,25,55]$. However, relatively homogeneous segments of agents can often be identified based on observed or unobserved characteristics [56,57]. The support of particular key segments can be crucial for the success of renewable energy innovations, such as the key role of early adopters [30,37] in generating market acceptance. Accounting for heterogeneity in public acceptance studies, allows the identification of such key segments.

\subsection{Modeling preferences through choice processes}

Preferences for renewable energy technologies are revealed when a trade-off or choice between several alternatives is made. Choice processes can be described using a variety of economic and psychological models, varying from neoclassical rational choice models to mental models that are based on inductive search heuristics [58]. No single model is most appropriate in all circumstances; this depends on the purpose of its use. For our purposes, Random Utility Theory (RUT) [59-61] is especially informative. RUT is able to fit most of these theories in a realistic choice context.

Choice models commonly assume that agents derive utility from the attributes of alternatives in a given choice situation (e.g. a choice task). In each task agents choose the alternative with the highest utility. RUT shares this assumption, but accounts for the heterogeneity of individual agents and the context of the choice. In RUT, utility $(U)$ is a latent construct that consists of a deterministic component $(V)$, and an error component $(\varepsilon)$. The utility of alternative $j$ of agent $i$ is given by $[61,62]$ :

$U_{i j}=V_{i j}+\varepsilon_{i j}$

The value of $V_{i j}$ is determined by a set of observed attributes that are associated with alternative $j$ or with agent $i$. Each attribute is weighted by a coefficient $\beta_{i j}$. The error component $\varepsilon_{i j}$ is determined by factors such as unobserved attributes or agent characteristics, measurement error, functional misspecification and bounded rationality. Finally, it captures the aforementioned heterogeneity among citizens based on their choice behavior [57]. Overall, $\varepsilon_{i j}$ gives the choice model its probabilistic properties

Scholars typically prefer to base their studies on revealed preferences, which are deduced from economic agents' observed actions. This approach is appropriate for market and community acceptance, but cannot be used to measure socio-political acceptance, because revealed preference data is unavailable before market introduction. An alternative is to use data agents' self-reported preferences. These are referred to as stated preferences and can be measured using ordinal 
Table 1

Attribute levels of the energy alternatives.

\begin{tabular}{|c|c|c|c|c|c|}
\hline & $\begin{array}{l}\text { Long term problems } \\
\text { ( } 3 \text { levels) }\end{array}$ & $\begin{array}{l}\text { Security of supply } \\
\text { ( } 3 \text { levels) }\end{array}$ & $\begin{array}{l}\text { Private costs and } \\
\text { discomfort ( } 2 \text { levels) }\end{array}$ & $\begin{array}{l}\text { Spatial impact } \\
\text { (3 levels) }\end{array}$ & $\begin{array}{l}\text { Price per kW h } \\
\text { (continuous scale) }\end{array}$ \\
\hline Photovoltaic solar energy & Relatively low & Relatively low & Relatively high & Relatively low & $\pm € 0.20$ \\
\hline Offshore wind energy & Relatively low & Medium & Relatively low & Medium & $\pm € 0.07$ \\
\hline Onshore wind energy & Relatively low & Medium & Relatively low & Relatively high & $\pm € 0.045$ \\
\hline Energy from biomass & Medium & Relatively high & Relatively low & Relatively low & $\pm € 0.08$ \\
\hline Energy from coal & Relatively high & Relatively high & Relatively low & Relatively low & $\pm € 0.035$ \\
\hline Energy from coal with CCS & Medium & Relatively high & Relatively low & Relatively low & $\pm € 0.06$ \\
\hline Nuclear energy & Medium & Relatively high & Relatively low & Relatively low & $\pm € 0.04$ \\
\hline Energy from natural gas & Relatively high & Medium & Relatively low & Relatively low & $\pm € 0.045$ \\
\hline Energy from natural gas with CCS & Medium & Medium & Relatively low & Relatively low & $\pm € 0.06$ \\
\hline
\end{tabular}

ratings, ranking, or contingent valuation. These techniques are not without disadvantages. Studies have shown that agents typically struggle to express their preferences accurately when tradeoffs are complex and where respondents have only limited personal experience with the alternatives [63,64].

A more reliable technique is the Discrete Choice Experiment $[20,65,66]$. In a DCE, respondents are provided with a series of choice tasks, usually in the form of a questionnaire. Each task contains two or more alternatives between which respondents are asked to choose. Alternatives differ on a fixed number of attributes. It is common practice to include multiple questionnaires with systematically varying attribute levels and choice tasks in the experimental design. This can drastically increase the quantity and quality of data obtained through the questionnaire.

DCEs have a number of advantages over conventional preference measurement techniques. First, they force respondents to make tradeoffs between alternatives, which allows for the estimation of a full ranking of alternatives. This is often problematic for rating tasks [63] Second, attribute levels are part of a controlled experimental design. This prevents common method bias [67] and increases internal validity [68]. Third, the researcher can control the number of attributes and the information available to respondents in such a manner that choice tasks represent realistic "what if situations [69]. This is an improvement over traditional methods to measure preferences, where these factors cannot be controlled.

A number of DCEs have been conducted to measure preferences for energy technologies [70-77], focusing on adoption behavior and market acceptance. For socio-political acceptance the number of DCEs has increased rapidly in last few years see [12,70-72]. These studies focus on the consumer's willingness to pay for alternative energy sources. However, no studies have yet demonstrated how labeling and time affect acceptance of energy technologies among different classes of the public.

\section{Methods and data}

\subsection{Research design}

We measured the public preferences for renewable energy technologies with two identical discrete choice experiments (DCEs). Each DCE consisted of six binary choice tasks with six varying technological attributes in each task. Each choice task contained two technologies from which respondents were asked to pick their preferred option. Only the most prominent technologies that are of the energy portfolio in the Netherlands were included, namely (1) PV solar energy, (2) onshore wind energy, (3) offshore wind energy, (4) biomass energy, (5) nuclear energy, (6) energy from coal, (7) energy from coal with CCS, (8) energy from natural gas, and (9) energy from natural gas with CCS

The first technological attribute included in each choice task was the name of the technology. Half of the respondents received choice

\begin{tabular}{|c|c|c|}
\hline \multicolumn{2}{|c|}{$\begin{array}{c}\text { Which of the following two options do you prefer to form an } \\
\text { important part of the future Dutch energy system? }\end{array}$} \\
\hline Attribute & Option 1 & Option 2 \\
\hline Long term problems & Relatively low & Relatively high \\
Security of supply & Relatively low & Relatively high \\
Amount of effort & Relatively high & Relatively low \\
Spatial impact & Relatively low & Relatively high \\
Price (€ per kWh) & $\pm € 0.20$ & $\pm € 0.035$ \\
& & \\
\hline $\begin{array}{c}\text { Which of these two do } \\
\text { you prefer? }\end{array}$ & 0 & 0 \\
\hline
\end{tabular}

Fig. 1. An example choice task.

tasks with names of the technology in the heading (the labeled condition); the other half received choice tasks with "option 1" and "option 2" in the heading (the unlabeled condition). The remainder of the choice experiment was the same for both conditions. Each choice task contained five additional technological attributes. These attributes were based on the five latent factors identified by Van Rijnsoever and Farla [32] from a wide range of technology characteristics and using a sample of 450 respondents in the Netherlands. Each attribute was described and explained to the respondents before the DCE. These attributes were:

- Long-term problems ${ }^{2}$ : this attribute represents concerns about the catastrophic consequences that a technology might have. It contains all the aspects that Slovic [21] identifies as part of the risk perceptions of nuclear energy (e.g. unknown or dread risks). These perceptions are also applicable to the consequences of climate change. The attribute has three levels: "relatively low," "medium," and "relatively high."

- Security of supply: this attribute reflects the reliability of energy supply to a country. It mainly pertains to energy security and macro-economic issues. It includes concerns raised in the public debate about increasing energy dependence on politically instable countries [78,79]. The attribute has three levels: "relatively low," "medium," and "relatively high."

\footnotetext{
${ }^{2}$ Van Rijnsoever and Farla [32] called this attribute "risk of catastrophes." We choose the term "long-term problems," because it better reflects the content of the underlying attribute, sounds more neutral, and better accommodates the three levels attached to it.
} 
Table 2

The indicators for prior knowledge about energy technologies and environmental attitude *: items are reverse scored.

\begin{tabular}{|c|c|}
\hline Indicator & Latent construct \\
\hline $\begin{array}{l}\text { I know quite a lot about various energy technologies } \\
\text { I do not feel very knowledgeable about various energy technologies* } \\
\text { Among my circle of friends, I'm one of the "experts" on various energy technologies } \\
\text { Compared to most other people, I know less about various energy technologies } \\
\text { When it comes to energy technologies, I really don't know a lot. }\end{array}$ & Prior knowledge: alpha $=0.85$, mean $=14.41$, S.D. $=3.82$ \\
\hline $\begin{array}{l}\text { The earth is like a ship with very limited room and resources } \\
\text { Humans are severely abusing the environment } \\
\text { If things continue on their present course, we will soon experience a major ecological catastrophe } \\
\text { Humans will eventually learn enough about how nature works to be able to control it } \\
\text { Human ingenuity will insure that we do NOT make the earth unlivable } \\
\text { Humans were meant to rule over the rest of nature } \\
\text { The balance of nature is strong enough to cope with the impacts of modern industrial nations } \\
\text { The so-called "ecological crisis" facing humankind has been greatly exaggerated } \\
\text { When humans interfere with nature it often produces disastrous consequences } \\
\text { The balance of nature is very delicate and easily upset } \\
\text { Plants and animals have as much right as humans to exist }\end{array}$ & Environmental awareness: alpha $=0.74$, mean $=49.65$ S.D. $=6.56$ \\
\hline
\end{tabular}

- Private costs and discomfort: this attribute reflects how much perceived effort consumers have to put in to gain access to energy from a specific technology. This is mainly an issue with obtaining energy from micro-generation technologies, which substantial effort on the part of consumers (e.g. searching for information about subsidies). This can be a barrier to successful implementation [80]. The attribute has two levels: "relatively low" and "relatively high."

- Spatial impact: this attribute reflects the impact that a technology has on landscapes and the local environment. An example of a technology that has high spatial impact is onshore wind energy [6]. The attribute has three levels: "relatively low," "medium," and "relatively high."

- Price per kW h: this attribute reflects the economic competitiveness of an alternative and is an important attribute in the public debate on all technologies. The attribute is expressed in $€$ per $\mathrm{kW}$ h.

The values of the levels for each technology were based on a review of scientific and policy documents and verified by academic experts in the field of energy research. The levels of the attributes were fixed for each technology, these are presented in Table 1. A sample task is presented in Fig. 1.

All possible combinations of the nine energy technologies were included in the DCE, which amounted to 72 different choice tasks. Using factorial blocking, the tasks were divided into 12 sets of 6 tasks. Together the sets of choice tasks formed an orthogonal experimental design (i.e. there was no correlation between attributes in the design). Since there was a labeled and an unlabeled condition, 24 versions of the questionnaire were distributed.

\subsection{Data collection and measurement}

The data were collected in the Dutch province of Utrecht. Utrecht is a province in the center of the Netherlands and has 1.2 million inhabitants. It contains two large cities and numerous towns and villages of varying sizes. The first survey was conducted in March 2010 and the second in January 2012. In the intervening period the nuclear incident at Fukushima took place, constituting a potential source of change in public acceptance between the two measurements. In 2010, university students ${ }^{3}$ personally delivered 1500 questionnaires to households throughout the province of Utrecht. A few days after

\footnotetext{
${ }^{3}$ All students were trained prior to delivering the questionnaires. They received instructions about how to approach respondents, how to administer the questionnaires, and about scientific fraud.
}

delivery, they collected the completed questionnaires. Quota by sex, age, and municipality of the respondents were used to obtain a representative sample. A total of 916 households were successfully surveyed in this manner. The mean age was 43.65 years and $51.3 \%$ of the respondents were female. Better-educated respondents were slightly overrepresented.

In January 2012, 10 months after the Fukushima incident, the same procedure was repeated in the same region with a new sample of respondents. A total of 1800 questionnaires were distributed, of which 1,448 were completed. The mean age was 45.87 years and $47.6 \%$ of the respondents were female. Better-educated respondents were again slightly overrepresented.

Using a new sample minimized the influence of the 2010 experimental treatment on the preferences in 2012. The downside is that it was not possible to measure change in preferences for individual respondents.

In addition to preferences for energy technologies, the questionnaire also measured a number of respondent characteristics: age, gender, education level, income, prior knowledge about energy technologies, and attitude towards the environment. Previous literature showed that these variables influence preferences for energy technologies attributes [32].

Prior knowledge about energy technologies was measured with an adapted version of the scale devised by Flynn and Goldsmith [81]. Environmental awareness was measured with the revised New Environmental Paradigm scale [82]. For both scales the Cronbach's Alpha was larger than the minimum threshold of 0.7. Item scores were summed to obtain a composite measure ${ }^{4}$. Table 2 gives the measurement and descriptive statistics for these two variables. There were no significant differences between the labeled and unlabeled condition for any respondent characteristics. Because of the large sample size, there were minor significant differences in respondent characteristics over time, the largest eta-square being 0.005 .

\section{Analysis and results}

\subsection{The influence of labeling and time on public acceptance}

The experiment included four experimental conditions; a labeled and an unlabeled condition in both 2010 and 2012. This allowed us to

\footnotetext{
${ }^{4}$ It should be noted that the environmental awareness scale has multiple dimensions. We explored if this yielded different and better models. However, this was not the case. Therefore we decided to treat environmental awareness as a onedimensional construct.
} 
Table 3

Mixed logit model. Task number, task position and scale class estimators are omitted.

\begin{tabular}{|c|c|c|c|c|c|c|c|c|c|c|c|c|c|c|c|c|}
\hline \multirow[t]{2}{*}{ Variable } & \multicolumn{3}{|c|}{ DCE 2010: unlabeled } & \multirow[t]{2}{*}{ Rank } & \multicolumn{3}{|c|}{ DCE 2010: labeled } & \multirow[t]{2}{*}{ Rank } & \multicolumn{3}{|c|}{ DCE 2012: unlabeled } & \multirow[t]{2}{*}{ Rank } & \multicolumn{3}{|c|}{ DCE 2012: labeled } & \multirow[t]{2}{*}{ Rank } \\
\hline & Estimator & Sig. & $\begin{array}{l}\text { Tech. } \\
\text { utility }\end{array}$ & & Estimator & Sig. & $\begin{array}{l}\text { Tech. } \\
\text { utility }\end{array}$ & & Estimator & Sig. & $\begin{array}{l}\text { Tech. } \\
\text { utility }\end{array}$ & & Estimator & Sig. & $\begin{array}{l}\text { Tech. } \\
\text { utility }\end{array}$ & \\
\hline Photovoltaic solar energy & -0.42 & $* * * *$ & -0.42 & 8 & 0.44 & $* * *$ & 0.02 & 4 & -0.02 & & -0.44 & 9 & 0.00 & & 0.01 & 5 \\
\hline Offshore wind energy & -0.02 & & -0.02 & 4 & 0.38 & $* * *$ & 0.35 & 1 & 0.02 & & -0.01 & 5 & -0.02 & & 0.35 & 1 \\
\hline Onshore wind energy & -0.21 & $* *$ & -0.21 & 7 & 0.19 & $*$ & -0.03 & 6 & 0.00 & & -0.21 & 7 & 0.08 & & 0.05 & 4 \\
\hline Energy from biomass & 0.06 & & 0.06 & 3 & 0.15 & & 0.22 & 2 & 0.01 & & 0.08 & 3 & 0.02 & & 0.25 & 2 \\
\hline Energy from coal & -0.18 & $* *$ & -0.18 & 6 & -0.23 & $*$ & -0.41 & 9 & -0.01 & & -0.19 & 6 & 0.06 & & -0.36 & 9 \\
\hline $\begin{array}{l}\text { Energy from coal with } \\
\text { CCS }\end{array}$ & 0.32 & $* * * *$ & 0.32 & 2 & -0.36 & $* * *$ & -0.04 & 7 & -0.01 & & 0.31 & 2 & -0.02 & & -0.07 & 6 \\
\hline Nuclear energy & 0.92 & $* * * *$ & 0.92 & 1 & -0.91 & $* * *$ & 0.00 & 5 & -0.04 & & 0.88 & 1 & -0.07 & & -0.10 & 7 \\
\hline Energy from natural gas & -0.43 & $* * *$ & -0.43 & 9 & 0.15 & & -0.28 & 8 & 0.01 & & -0.42 & 8 & 0.06 & & -0.21 & 8 \\
\hline $\begin{array}{l}\text { Energy from natural gas } \\
\text { with CCS }\end{array}$ & -0.04 & & -0.04 & 5 & 0.19 & $* *$ & 0.16 & 3 & 0.04 & & 0.00 & 4 & -0.12 & $* *$ & 0.07 & 3 \\
\hline Wald $\chi^{2}$ & 35.72 & $* * * *$ & & & 43.44 & $* * *$ & & & 1.76 & & & & 11.26 & & & \\
\hline McFadden $R^{2}$ & 0.33 & & & & & & & & & & & & & & & \\
\hline $\mathrm{BIC}$ & $16,182.90$ & & & & & & & & & & & & & & & \\
\hline
\end{tabular}

$* p<0.05$
$* * p<0.01$

$* * * * 0.001$.

determine if there is an effect of labeling and time on preferences for energy technologies.

Using the Latent Gold program we first estimated a mixed logit model. The dependent variable was a binary variable that indicated whether or not a technology was chosen. The model contained a nominal nine-level predictor that represented the technologies. Interaction effects between this predictor and a "labeling" variable (labeled or unlabeled condition) and "year" variable (2010 or 2012 condition) were added to the model. This produced four different technology rankings, one for each experimental condition. We added two control variables to the models; choice task number (1-6) and position in the choice task (left or right).

Prior to constructing the final rankings we explored whether scale classes existed among respondents. Respondents exhibit different degrees of consistency when making their choices, which can lead to a bias in model estimates [83,84]. Scale classes correct for this by clustering respondents who display a similar degree of consistency, based on the variance in their responses [85]. Each respondent receives a correction based on his or her scale class. We explored models with one to four scale classes. As is customary in latent class analysis see [86,87], the optimal number of scale classes was determined by selecting the model with the lowest Bayesian Information Criterion (BIC) see [88], which turned out to be a two-scale class model. We used the McFadden pseudo $R$ square [62] as indicator of model performance.

Table 3 presents the results of the model. The McFadden $R^{2}$ is 0.33 , which is acceptable. The estimators in the unlabeled condition of 2010 correspond to the utility that respondents assigned to the unlabeled technologies in 2010. Statistically significant differences indicate that the utility is different from zero. The estimators in the other columns represent the difference in utility compared with the unlabeled condition in 2010. The total utility of each technology is displayed in Table 3, along with its rank.

To determine if rankings were similar between conditions, we calculated the Spearman's $\rho$ for each pair of rankings. Finally, Wald $\chi^{2}$ indicates whether a variable contributes significantly to the prediction of public preferences for energy technologies.

The model shows that there are significant differences between the labeled and the unlabeled conditions, but that there are no significant differences between the conditions over time. Preferences remained relatively stable, despite the Fukushima incident.

The labeled condition is quite different from the unlabeled condition. The utilities of nuclear energy and energy from coal are signi- ficantly lower in the labeled condition, whereas the utilities of solar energy, wind energy and energy from natural gas with CCS are significantly higher. These differences are likely caused by the thoughts and associations generated by the labels of these technologies. This means that the labels are likely to have invoked heuristic processing, while the attributes of the unlabeled condition are more likely to have led to elaborate processing.

Although the impact of time is rather limited, preferences in the labeled condition are slightly more dynamic than in the unlabeled condition. Nuclear energy drops from the fifth to seventh place in the ranking, but this change is not statistically significant. This means there is no overall population effect of the incident at Fukushima on the preferences for nuclear energy.

\subsection{Exploring heterogeneity using latent class analysis}

We extended the mixed logit model to a latent class model to explore heterogeneity among the respondents see [57]. The classes are based on respondent characteristics and on the extent to which respondents made similar choices. We explored latent classes using two approaches.

- First, we estimated a "restricted" latent class model that identifies separate classes within the labeled and unlabeled conditions. This gives insight into whether different classes exist within each condition and whether the composition of these classes differs between conditions.

- Second, we estimated a "free" latent class model in which we removed the restriction that classes can only be identified within experimental conditions. Unlike the restricted model, the free model shows the importance of labeling with regard to the preferences for different latent classes.

Because preferences in the mixed logit model hardly changed over time, we do not present latent-class models that identify separate classes within the measurement year conditions. Again, the BIC was used to determine the optimal number of classes.

\subsection{Results of the restricted model}

Tables $4 \mathrm{a}$ and $4 \mathrm{~b}$ shows the results of the restricted model. Table $4 \mathrm{a}$ shows for each class the estimates for the different technologies and Table $4 \mathrm{~b}$ shows how the classes differ by respondent characteristics. 
Table 4a

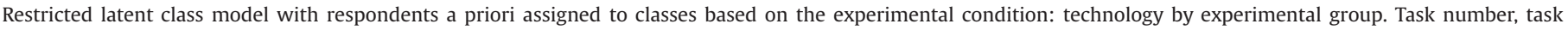
position and scale class estimators are omitted.

\begin{tabular}{|c|c|c|c|c|c|c|c|c|c|}
\hline \multirow[t]{2}{*}{ Class } & \multirow[t]{2}{*}{ Variable } & \multicolumn{4}{|l|}{ DCE 2010} & \multicolumn{4}{|l|}{ DCE 2012} \\
\hline & & Estimator & Sig. & Utility & Rank & Estimator & Sig. & Utility & Rank \\
\hline 1 & Photovoltaic solar energy & 1.39 & & 1.39 & 7 & -0.34 & & 1.05 & 7 \\
\hline$N=276$ & Offshore wind energy & 2.48 & $*$ & 2.48 & 1 & -0.70 & & 1.78 & 1 \\
\hline $11.7 \%$ & Onshore wind energy & 2.40 & $*$ & 2.40 & 2 & -0.66 & & 1.74 & 2 \\
\hline \multirow[t]{7}{*}{ Unlabeled } & Energy from biomass & 1.62 & & 1.62 & 6 & -0.42 & & 1.20 & 5 \\
\hline & Energy from coal & -4.45 & & -4.45 & 8 & 0.96 & & -3.50 & 8 \\
\hline & Energy from coal with CCS & 2.24 & $*$ & 2.24 & 4 & -0.68 & & 1.56 & 4 \\
\hline & Nuclear energy & 2.34 & $*$ & 2.34 & 3 & -0.65 & & 1.69 & 3 \\
\hline & Energy from natural gas & -9.67 & & -9.67 & 9 & 2.98 & & -6.69 & 9 \\
\hline & Energy from natural gas with CCS & 1.65 & & 1.65 & 5 & -0.48 & & 1.17 & 6 \\
\hline & $N$ per group & 116 & & & & 160 & & & \\
\hline 2 & Photovoltaic solar energy & -1.11 & $*$ & -1.11 & 8 & -0.04 & & -1.14 & 9 \\
\hline$N=559$ & Offshore wind energy & -0.09 & & -0.09 & 6 & 0.10 & & 0.01 & 5 \\
\hline $23.6 \%$ & Onshore wind energy & -1.26 & $* *$ & -1.26 & 9 & 0.16 & & -1.09 & 7 \\
\hline \multirow[t]{7}{*}{ Unlabeled } & Energy from biomass & 0.18 & & 0.18 & 4 & 0.01 & & 0.19 & 3 \\
\hline & Energy from coal & 0.87 & & 0.87 & 3 & -0.94 & $*$ & -0.07 & 6 \\
\hline & Energy from coal with CCS & 1.03 & & 1.03 & 2 & -0.01 & & 1.03 & 2 \\
\hline & Nuclear energy & 1.40 & & 1.40 & 1 & 0.70 & & 2.10 & 1 \\
\hline & Energy from natural gas & -1.06 & $*$ & -1.06 & 7 & -0.05 & & -1.11 & 8 \\
\hline & Energy from natural gas with CCS & 0.03 & & 0.03 & 5 & 0.06 & & 0.09 & 4 \\
\hline & $N$ per group & 212 & & & & 347 & & & \\
\hline 3 & Photovoltaic solar energy & 0.63 & & 0.63 & 1 & -1.01 & $*$ & -0.37 & 9 \\
\hline$N=363$ & Offshore wind energy & -0.11 & & -0.11 & 6 & 0.07 & & -0.04 & 8 \\
\hline $15.4 \%$ & Onshore wind energy & 0.03 & & 0.03 & 3 & 0.01 & & 0.03 & 4 \\
\hline \multirow[t]{7}{*}{ Unlabeled } & Energy from biomass & -0.17 & & -0.17 & 8 & 0.16 & $*$ & -0.02 & 6 \\
\hline & Energy from coal & -0.21 & & -0.21 & 9 & 0.29 & $* *$ & 0.08 & 3 \\
\hline & Energy from coal with CCS & -0.09 & & -0.09 & 4 & 0.17 & $*$ & 0.08 & 2 \\
\hline & Nuclear energy & 0.18 & & 0.18 & 2 & 0.11 & & 0.29 & 1 \\
\hline & Energy from natural gas & -0.11 & & -0.11 & 5 & 0.10 & & -0.01 & 5 \\
\hline & Energy from natural gas with CCS & -0.14 & & -0.14 & 7 & 0.11 & & -0.03 & 7 \\
\hline & $N$ per group & 138 & & & & 225 & & & \\
\hline 4 & Photovoltaic solar energy & -0.53 & & -0.53 & 6 & 0.88 & $*$ & 0.35 & 4 \\
\hline$N=343$ & Offshore wind energy & 2.36 & $*$ & 2.36 & 1 & -0.44 & & 1.92 & 1 \\
\hline $14.5 \%$ & Onshore wind energy & -0.38 & & -0.38 & 4 & 0.89 & $* * *$ & 0.51 & 2 \\
\hline \multirow[t]{7}{*}{ Labeled } & Energy from biomass & -0.48 & & -0.48 & 5 & 0.97 & $* * *$ & 0.49 & 3 \\
\hline & Energy from coal & -1.34 & & -1.34 & 7 & 0.10 & & -1.25 & 7 \\
\hline & Energy from coal with CCS & 1.68 & $* * * *$ & 1.68 & 3 & -1.37 & $* * * *$ & 0.31 & 6 \\
\hline & Nuclear energy & -1.55 & $*$ & -1.55 & 9 & 0.20 & & -1.35 & 9 \\
\hline & Energy from natural gas & -1.46 & $*$ & -1.46 & 8 & 0.14 & & -1.31 & 8 \\
\hline & Energy from natural gas with CCS & 1.70 & $* * * *$ & 1.70 & 2 & -1.37 & $* * * *$ & 0.33 & 5 \\
\hline & $N$ per group & 127 & & & & 216 & & & \\
\hline 5 & Photovoltaic solar energy & -0.05 & & -0.05 & 6 & -0.03 & & -0.08 & 8 \\
\hline$N=477$ & Offshore wind energy & 0.04 & & 0.04 & 4 & 0.03 & & 0.06 & 3 \\
\hline $20.2 \%$ & Onshore wind energy & -0.07 & & -0.07 & 8 & 0.01 & & -0.06 & 6 \\
\hline \multirow{7}{*}{ Labeled } & Energy from biomass & 0.15 & $* *$ & 0.15 & 1 & -0.05 & $*$ & 0.10 & 1 \\
\hline & Energy from coal & -0.07 & & -0.07 & 7 & 0.00 & & -0.07 & 7 \\
\hline & Energy from coal with CCS & 0.08 & & 0.08 & 3 & -0.03 & & 0.05 & 4 \\
\hline & Nuclear energy & 0.10 & & 0.10 & 2 & -0.01 & & 0.10 & 2 \\
\hline & Energy from natural gas & -0.18 & $* *$ & -0.18 & 9 & 0.05 & & -0.12 & 9 \\
\hline & Energy from natural gas with CCS & -0.01 & & -0.01 & 5 & 0.03 & & 0.02 & 5 \\
\hline & $N$ per group & 184 & & & & 293 & & & \\
\hline 6 & Photovoltaic solar energy & 0.97 & & 0.97 & 7 & -0.17 & & 0.80 & 6 \\
\hline$N=346$ & Offshore wind energy & 1.17 & & 1.17 & 3 & -0.22 & & 0.96 & 1 \\
\hline $14.6 \%$ & Onshore wind energy & 1.15 & & 1.15 & 4 & -0.26 & & 0.89 & 4 \\
\hline \multirow[t]{7}{*}{ Labeled } & Energy from biomass & 1.10 & & 1.10 & 5 & -0.19 & & 0.91 & 2 \\
\hline & Energy from coal & -7.04 & & -7.04 & 9 & 2.46 & & -4.58 & 9 \\
\hline & Energy from coal with CCS & -3.17 & $*$ & -3.17 & 8 & 1.77 & $*$ & -1.40 & 8 \\
\hline & Nuclear energy & 3.65 & $* * * *$ & 3.65 & 1 & -2.91 & $* * * *$ & 0.74 & 7 \\
\hline & Energy from natural gas & 0.97 & & 0.97 & 6 & -0.17 & & 0.80 & 5 \\
\hline & Energy from natural gas with CCS & 1.19 & $*$ & 1.19 & 2 & -0.30 & & 0.89 & 3 \\
\hline & $N$ per group & 139 & & & & 207 & & & \\
\hline Wald $\chi^{2}$ & & 139.96 & $* * * *$ & & & 147.72 & $* * * *$ & & \\
\hline Wald $\chi^{2}(=)$ & & 133.73 & $* * * *$ & & & 142.62 & $* * * *$ & & \\
\hline McFadden $R^{2}$ & & 0.56 & & & & & & & \\
\hline $\mathrm{BIC}$ & & $19,143.07$ & & & & & & & \\
\hline
\end{tabular}

$* p<0.05$.

$* * * 0.01$.

$* * * * 0.001$. 


\section{Table 4b}

Restricted latent class model with respondents a priori assigned to classes based on the experimental condition: Respondent characteristics. Task number, task position and scale class estimators are omitted.

\begin{tabular}{|c|c|c|c|}
\hline Variable & Class & Estimator & Sig. \\
\hline $\begin{array}{l}\text { Intercept } \\
\text { Wald } \chi^{2}: 112.44^{* * * *}\end{array}$ & $\begin{array}{l}1 \\
2 \\
3 \\
4 \\
5 \\
6\end{array}$ & $\begin{array}{l}-5.13 \\
0.35 \\
5.22 \\
-4.33 \\
4.80 \\
-0.90\end{array}$ & $\begin{array}{l}* * * * \\
* * * \\
* * * \\
* * * *\end{array}$ \\
\hline $\begin{array}{l}\text { Gender } \\
\text { Wald } \chi^{2}: 20.37^{* * *}\end{array}$ & $\begin{array}{l}1 \\
2 \\
3 \\
4 \\
5 \\
6\end{array}$ & $\begin{array}{l}0.43 \\
-0.09 \\
-0.40 \\
0.36 \\
-0.33 \\
0.03\end{array}$ & $\begin{array}{l}* * * \\
* * \\
* \\
* *\end{array}$ \\
\hline $\begin{array}{l}\text { Age } \\
\text { Wald } \chi^{2}: 33.15^{* * * *}\end{array}$ & $\begin{array}{l}1 \\
2 \\
3 \\
4 \\
5 \\
6\end{array}$ & $\begin{array}{l}-0.01 \\
0.00 \\
0.00 \\
0.00 \\
-0.01 \\
0.03\end{array}$ & $* * * *$ \\
\hline $\begin{array}{l}\text { Education level } \\
\text { Wald } \chi^{2}: 30.69^{* * * *}\end{array}$ & $\begin{array}{l}1 \\
2 \\
3 \\
4 \\
5 \\
6\end{array}$ & $\begin{array}{l}0.22 \\
0.00 \\
-0.18 \\
0.04 \\
-0.12 \\
0.05\end{array}$ & $\begin{array}{l}* * * * * \\
* * * * * \\
* * * * *\end{array}$ \\
\hline $\begin{array}{l}\text { Prior knowledge } \\
\text { Wald } \chi^{2}: 13.11^{*}\end{array}$ & $\begin{array}{l}1 \\
2 \\
3 \\
4 \\
5 \\
6\end{array}$ & $\begin{array}{l}0.04 \\
-0.03 \\
0.00 \\
0.05 \\
-0.02 \\
-0.02\end{array}$ & $\begin{array}{l}* \\
*\end{array}$ \\
\hline Environmental awareness & $\begin{array}{l}1 \\
2\end{array}$ & $\begin{array}{l}0.05 \\
0.01\end{array}$ & $* * * *$ \\
\hline Wald $\chi^{2}: 72.17^{* * * *}$ & $\begin{array}{l}3 \\
4 \\
5 \\
6\end{array}$ & $\begin{array}{l}-0.07 \\
0.06 \\
-0.05 \\
-0.01\end{array}$ & $\begin{array}{l}* * * * \\
* * * * * \\
* * * *\end{array}$ \\
\hline $\begin{array}{l}\text { Income } \\
\text { Wald } \chi^{2}: 6.49\end{array}$ & $\begin{array}{l}1 \\
2 \\
3 \\
4 \\
5 \\
6\end{array}$ & $\begin{array}{l}0.04 \\
0.04 \\
-0.10 \\
0.00 \\
-0.05 \\
0.08\end{array}$ & \\
\hline
\end{tabular}

$$
\begin{aligned}
& * p<0.05 \\
& * * p<0.01 \\
& * * * p<0.001
\end{aligned}
$$

The BIC showed that a six-class model with three classes in the unlabeled condition and three classes in the labeled condition best captures respondent heterogeneity. The Wald statistics revealed significant differences between the classes. There was no significant influence of the year variable on clustering $\left(\chi^{2}=2.24, \mathrm{df}=5, p=0.82\right)$. The overall McFadden $R^{2}$ was 0.56 , which is very good. Note that few technology estimators appear to be significant. These significance levels indicate that there are few differences in utility across conditions. This does not imply, however, that there are no differences between classes or between the utilities within a condition.

The six classes identified have the following differences in preferences:

- Class 1 - low-cost sustainability - (unlabeled, 11.7\% of respondents): the members of this class prefer wind energy, nuclear energy, and energy from coal or natural gas with CCS. This implies that they seek to reduce long-term problems, such as the effects of climate change, against the lowest possible costs.
The ranking of technologies is very stable over time $(\rho=0.98)$. The members of this class are more aware of the environment, are more likely to be female, and are better educated.

- Class 2 - low-cost energy - (unlabeled, 23.6\% of respondents): the preferences of this class resemble the mixed logit model closely and the rankings are highly correlated $\left(\rho_{2010}=0.82\right.$; $\left.\rho_{2012}=0.97\right)$. Nuclear energy is the preferred alternative, followed by energy from coal with or without CCS. Members of this class prefer technologies that lead to a cheap and reliable supply of electricity. The preferences of this class are also quite stable over time $(\rho=0.85)$. Members of this class are less knowledgeable about energy technologies than members of other classes.

- Class 3 - indifferent - (unlabeled, 15.4\% of respondents): a notable feature of this class is that the differences in utility of alternatives are relatively small and that only a few estimators are significant. This implies that its members are indifferent about energy technologies. This is supported by the fact that there is no evident pattern in the attributes of technologies that they prefer. Although the absolute changes in estimators over time are small, they result in a relatively large change in the rankings. The 2012 ranking is uncorrelated with that of 2010 $(\rho=0.05)$, which indicates that convictions are not strong in this class. Members of this class are more likely to be male, less educated, and care less about the environment.

- Class 4 - sustainability - (labeled, $14.5 \%$ of respondents): members of this class prefer renewable energy technologies or fossil fuel technologies with CCS. Preferences change slightly over time. In 2012, fossil fuel technologies with CCS were preferred less, whereas onshore wind energy, biomass energy, and solar energy were preferred more. The rankings are still strongly correlated $(\rho=0.83)$. The members of this class are more aware of the environment, more likely to be female, and more knowledgeable about energy technologies.

- Class 5 - indifferent - (labeled, 20.2\% of respondents): members of this class seem to be indifferent to energy technologies as the differences in utility are small and not significant. In contrast to the other indifferent class (3), there is little change in rankings over time $(\rho=0.92)$, and no evident effect of external events on preferences. This may be related to their indifference. Members of this class are more likely to be male, younger, less educated, and score lower on environmental awareness.

- Class 6 - swing away from nuclear energy - (labeled, 14.6\% of respondents): the most notable feature of this class is that preferences for specific technologies change substantially over time $(\rho=0.57)$. Nuclear energy drops from first place in the ranking to seventh place. This change is likely due to the incident at Fukushima, which implies that this class is more responsive to external events. Members of this class are older than average.

Overall, preferences in the labeled condition changed more over time than preferences in the unlabeled condition. The latent class analysis shows that within the unlabeled condition two classes have stable - but different - preferences and that one particular class of respondents is indifferent to the alternatives. The change in preferences of this class can only be explained by a change in valuation of attributes. In the labeled condition the preferences are also relatively stable in two classes, but again quite different. In class 4, nuclear energy is ranked lowest in both years, whereas in class 5 it ranks second in both years. However, in class 6 respondents changed their preferences, possibly in relation to the Fukushima incident. This suggests that a shift in public acceptance is not a population-wide move but that only a limited number of people change their preferences after such an incident.

A second interesting observation is that in both conditions a class exists which is relatively indifferent towards the topic (class 3 and 5). 
Table 5a

Free latent class model with no class restrictions. Technology by experimental group. Task number, task position and scale class estimators are omitted.

\begin{tabular}{|c|c|c|c|c|c|c|c|c|c|c|c|c|c|c|c|c|c|}
\hline \multirow[t]{2}{*}{ Class } & \multirow[t]{2}{*}{ Variable } & \multicolumn{3}{|c|}{ DCE 2010: unlabelled } & \multirow[t]{2}{*}{ Rank } & \multicolumn{3}{|c|}{ DCE 2010: labelled } & \multirow[t]{2}{*}{ Rank } & \multicolumn{3}{|c|}{ DCE 2012: unlabelled } & \multirow[t]{2}{*}{ Rank } & \multicolumn{3}{|c|}{ DCE 2012: labelled } & \multirow[t]{2}{*}{ Rank } \\
\hline & & Estimator & Sig. & $\begin{array}{l}\text { Tech. } \\
\text { utility }\end{array}$ & & Estimator & Sig. & $\begin{array}{l}\text { Tech. } \\
\text { utility }\end{array}$ & & Estimator & Sig. & $\begin{array}{l}\text { Tech. } \\
\text { utility }\end{array}$ & & Estimator & Sig. & $\begin{array}{l}\text { Tech. } \\
\text { utility }\end{array}$ & \\
\hline 1 & $\begin{array}{l}\text { Photovoltaic solar } \\
\text { energy }\end{array}$ & -2.96 & & -2.96 & 8 & 2.40 & & -0.56 & 7 & 0.51 & & -2.45 & 9 & -0.01 & & -0.07 & 3 \\
\hline \multirow[t]{9}{*}{$N=909$} & Offshore wind energy & -2.39 & & -2.39 & 6 & 1.96 & & -0.44 & 5 & 1.12 & & -1.27 & 5 & -0.59 & & 0.09 & 2 \\
\hline & Onshore wind energy & -3.10 & $*$ & -3.10 & 9 & 1.83 & & -1.27 & 9 & 0.78 & & -2.31 & 7 & 0.08 & & -0.40 & 7 \\
\hline & Energy from biomass & 2.19 & & 2.19 & 3 & 0.82 & & 3.01 & 1 & -1.10 & & 1.09 & 3 & -0.12 & & 1.78 & 1 \\
\hline & Energy from coal & -1.30 & & -1.30 & 4 & 1.18 & & -0.12 & 4 & -0.19 & & -1.49 & 6 & -0.24 & & -0.55 & 9 \\
\hline & $\begin{array}{l}\text { Energy from coal with } \\
\text { CCS }\end{array}$ & 4.78 & & 4.78 & 2 & -4.50 & & 0.28 & 3 & -1.76 & & 3.02 & 2 & 1.22 & & -0.25 & 6 \\
\hline & Nuclear energy & 7.69 & & 7.69 & 1 & -6.87 & & 0.82 & 2 & -0.80 & & 6.89 & 1 & -0.11 & & -0.10 & 5 \\
\hline & $\begin{array}{l}\text { Energy from natural } \\
\text { gas }\end{array}$ & -2.87 & & -2.87 & 7 & 1.64 & & -1.23 & 8 & 0.48 & & -2.39 & 8 & 0.33 & & -0.42 & 8 \\
\hline & $\begin{array}{l}\text { Energy from natural } \\
\text { gas with CCS }\end{array}$ & -2.05 & & -2.05 & 5 & 1.55 & & -0.50 & 6 & 0.97 & & -1.08 & 4 & -0.56 & & -0.09 & 4 \\
\hline & $N$ per group & 191 & & & & 158 & & & & 306 & & & & 254 & & & \\
\hline 2 & $\begin{array}{l}\text { Photovoltaic solar } \\
\text { energy }\end{array}$ & 0.54 & & 0.54 & 1 & -0.58 & & -0.05 & 6 & -0.87 & $* *$ & -0.33 & 9 & 0.80 & $*$ & -0.12 & 8 \\
\hline \multirow[t]{9}{*}{$N=893$} & Offshore wind energy & -0.07 & & -0.07 & 6 & 0.25 & $*$ & 0.18 & 2 & 0.02 & & -0.05 & 7 & -0.02 & & 0.17 & 1 \\
\hline & Onshore wind energy & 0.02 & & 0.02 & 3 & 0.32 & $* *$ & 0.34 & 1 & -0.02 & & 0.00 & 4 & -0.19 & $* *$ & 0.12 & 2 \\
\hline & Energy from biomass & -0.31 & $* * *$ & -0.31 & 9 & 0.13 & & -0.19 & 7 & 0.22 & $* * *$ & -0.09 & 8 & -0.08 & & -0.05 & 6 \\
\hline & Energy from coal & -0.05 & & -0.05 & 4 & -0.16 & & -0.21 & 9 & 0.19 & $*$ & 0.14 & 2 & -0.16 & & -0.18 & 9 \\
\hline & $\begin{array}{l}\text { Energy from coal with } \\
\text { CCS }\end{array}$ & -0.07 & & -0.07 & 7 & -0.12 & & -0.19 & 8 & 0.17 & $* *$ & 0.09 & 3 & -0.05 & & -0.08 & 7 \\
\hline & Nuclear energy & 0.13 & & 0.13 & 2 & -0.17 & & -0.04 & 5 & 0.16 & & 0.29 & 1 & -0.06 & & 0.06 & 4 \\
\hline & $\begin{array}{l}\text { Energy from natural } \\
\text { gas }\end{array}$ & -0.07 & & -0.07 & 5 & 0.19 & $*$ & 0.12 & 3 & 0.05 & & -0.01 & 5 & -0.19 & $* *$ & -0.01 & 5 \\
\hline & $\begin{array}{l}\text { Energy from natural } \\
\text { gas with CCS }\end{array}$ & -0.11 & & -0.11 & 8 & 0.15 & & 0.04 & 4 & 0.08 & & -0.03 & 6 & -0.04 & & 0.08 & 3 \\
\hline & $N$ per group & 163 & & & & 172 & & & & 262 & & & & 296 & & & \\
\hline 3 & $\begin{array}{l}\text { Photovoltaic solar } \\
\text { energy }\end{array}$ & 1.59 & & 1.59 & 7 & -2.14 & & -0.54 & 6 & -0.51 & & 1.08 & 7 & 1.37 & & 0.32 & 4 \\
\hline \multirow[t]{13}{*}{$N=562$} & Offshore wind energy & 2.92 & $*$ & 2.92 & 1 & 0.43 & & 3.35 & 1 & -1.00 & & 1.93 & 1 & 0.06 & & 2.42 & 1 \\
\hline & Onshore wind energy & 2.73 & $*$ & 2.73 & 2 & -2.10 & & 0.63 & 4 & -0.93 & & 1.80 & 2 & 1.31 & & 1.02 & 3 \\
\hline & Energy from biomass & 1.94 & & 1.94 & 6 & -1.36 & & 0.59 & 5 & -0.66 & & 1.28 & 5 & 1.11 & & 1.04 & 2 \\
\hline & Energy from coal & -5.38 & & -5.38 & 8 & 3.05 & & -2.33 & 8 & 1.69 & & -3.69 & 8 & -1.12 & & -1.76 & 8 \\
\hline & $\begin{array}{l}\text { Energy from coal with } \\
\text { CCS }\end{array}$ & 2.47 & $*$ & 2.47 & 4 & -1.15 & & 1.31 & 3 & -0.89 & & 1.58 & 4 & -0.18 & & 0.25 & 6 \\
\hline & Nuclear energy & 2.65 & $*$ & 2.65 & 3 & -5.12 & $* *$ & -2.47 & 9 & -0.90 & & 1.75 & 3 & 1.51 & & -1.86 & 9 \\
\hline & $\begin{array}{l}\text { Energy from natural } \\
\text { gas }\end{array}$ & -10.93 & & -10.93 & 9 & 8.82 & & -2.10 & 7 & 3.96 & & -6.97 & 9 & -3.58 & & -1.73 & 7 \\
\hline & $\begin{array}{l}\text { Energy from natural } \\
\text { gas with CCS }\end{array}$ & 2.00 & & 2.00 & 5 & -0.45 & & 1.55 & 2 & -0.75 & & 1.24 & 6 & -0.49 & & 0.31 & 5 \\
\hline & $N$ per group & 112 & & & & 120 & & & & 164 & & & & 166 & & & \\
\hline & Wald & 44.79 & $* *$ & & & 52.03 & $* * * *$ & & & 54.76 & $* * *$ & & & 50.42 & $* * k$ & & \\
\hline & Wald $\chi^{2}(=)$ & 36.55 & $* *$ & & & 41.42 & $* * * *$ & & & 47.69 & $* * * *$ & & & 44.28 & $* * * *$ & & \\
\hline & McFadden $R^{2}$ & 0.55 & & & & & & & & & & & & & & & \\
\hline & $\mathrm{BIC}$ & $15,764.76$ & & & & & & & & & & & & & & & \\
\hline
\end{tabular}

$* p<0.05$.

*** $p<0.01$.

$* * * * 0.001$.

Both classes share similar socio-demographic characteristics: they are male, less educated, and less aware of the environment.

\subsection{Results of the free model}

Tables 5a and 5b presents the results of the free model, Table 5a the estimators of the alternatives, and Table $5 \mathrm{~b}$ the respondent characteristics. The BIC indicates that a three-class model gives the best solution. The overall McFadden $R$-square is 0.55 , which indicates a good fit. Labeling is a significant predictor of class membership $\left(\chi^{2}=9.76\right.$, $\mathrm{df}=2, p=0.01)$, whereas year is not $\left(\chi^{2}=2.14, \mathrm{df}=2, p=0.34\right)$.

- Class 1 - swing towards sustainability - (38.5\% of respondents): members of this class prefer nuclear energy, energy from coal with CCS, and biomass energy in the unlabeled condition, similar to the mixed logit model. The ranking changes little over time, as evidenced by the strong correlation between the rankings of both measurement years $(\rho=0.90)$. The ranking in the 2010 labeled condition is very similar and correlates strongly with the rankings in both unlabeled conditions $\left(\rho_{2010}=\right.$ 0.92; $\rho_{2012}=0.82$ ). The ranking in the labeled condition, however, changed considerably over time $(\rho=0.37)$. In the 2012 labeled condition, biomass energy remains the most preferred option, but the top three now also contain offshore wind energy and solar energy. Overall, this means that the valuation of observed attributes by members of this class does not change over time, but that their valuation of inferred attributes does change. This resulted in a shift of preferences towards renewable energy. Notable about members of this class is that they are significantly older than the other classes and have a higher income.

- Class 2 - indifferent - (37.8\% of respondents): members of class 2 are less pronounced in their preferences than members of 
other classes. This is evidenced by the smaller estimators and by the lack of consistency in the attributes of the unlabeled technologies they preferred in 2010 (solar energy, nuclear energy and onshore wind energy). The unlabeled preference ranking was completely overturned in $2012(\rho=0.23)$, which implies that the members of this class changed their valuation of technology attributes over time. However, there is little change in preferences for labeled technologies between 2010 and $2012\left(\rho_{2010}=0.88\right)$. This suggests that unobserved attributes have not changed significantly and that any events between 2010 and 2012 have had little influence on preferences. Further, it is evident from the lack of correspondence between labeled and unlabeled technologies $\left(\rho_{2010}=0.13 ; \rho_{2012}=-0.07\right)$ that technology labeling dominates the observed attributes in the choice process of this class. Table 5b shows that members of this class are more likely to be male, less educated, and less knowledgeable about energy technologies, have lower environmental attitudes, and have a lower income.

Table 5b

Free latent class model with no class restrictions. Respondent characteristics. Task number, task position and scale class estimators are omitted.

\begin{tabular}{|c|c|c|c|}
\hline & Class & Estimator & Sig. \\
\hline Intercept & 1.00 & -0.43 & \\
\hline \multirow[t]{2}{*}{ Wald $\chi^{2}: 123.8011^{* * * * *}$} & 2.00 & 5.41 & $* * * *$ \\
\hline & 3.00 & -4.98 & $* * * * *$ \\
\hline Gender & 1.00 & -0.15 & \\
\hline \multirow[t]{2}{*}{ Wald $\chi^{2}: 25.5559^{* * * * *}$} & 2.00 & -0.36 & $* * * *$ \\
\hline & 3.00 & 0.51 & $* * * *$ \\
\hline Age & 1.00 & 0.01 & $* * *$ \\
\hline \multirow[t]{2}{*}{ Wald $\chi^{2}: 7.3627^{*}$} & 2.00 & 0.00 & \\
\hline & 3.00 & -0.01 & \\
\hline Educ & 1.00 & -0.02 & \\
\hline \multirow[t]{2}{*}{ Wald $\chi^{2}: 22.2769^{* * * * *}$} & 2.00 & -0.13 & $* * *$ \\
\hline & 3.00 & 0.14 & $* * * *$ \\
\hline Prior knowledge & 1.00 & -0.01 & \\
\hline \multirow[t]{2}{*}{ Wald $\chi^{2}: 13.2474^{* * *}$} & 2.00 & -0.04 & \\
\hline & 3.00 & 0.04 & \\
\hline Environmental awareness & 1.00 & 0.01 & \\
\hline \multirow[t]{2}{*}{ Wald $\chi^{2}: 80.9228^{* * * * k}$} & 2.00 & -0.06 & $* *$ \\
\hline & 3.00 & 0.05 & $* * * * *$ \\
\hline Income & 1.00 & 0.06 & $*$ \\
\hline \multirow[t]{2}{*}{ Wald $\chi^{2}: 9.554^{* * *}$} & 2.00 & -0.09 & $* * * *$ \\
\hline & 3.00 & 0.03 & \\
\hline
\end{tabular}

$$
\begin{aligned}
& * p<0.05 \\
& * * p<0.01 \\
& * * * p<0.001
\end{aligned}
$$

- Class 3 - low-cost sustainability - (23.8\% of the respondents): the rankings of the unlabeled condition in 2010 and 2012 are virtually identical $(\rho=0.98)$, which means that there was little change over time in the valuation of technology attributes. The members of this class prefer wind energy and nuclear energy when the technologies are unlabeled. Energy from coal and natural gas is least preferred. This finding can be explained by a preference for reducing long-term consequences against the lowest price. In the labeled 2010 condition, members' preferences shift to offshore wind energy, followed by energy from coal or gas in combination with CCS. This is largely because nuclear energy is negatively valued in the labeled condition. In the labeled 2012 condition, fossil fuel technologies had lower utilities, while non-fossil fuel technologies had increased utilities. In both years there was only a moderate correlation between labeled and unlabeled rankings $\left(\rho_{2010}=0.53 ; \rho_{2012}=\right.$ 0.47). The effect of labeling differed somewhat between 2010 and 2012, as evidenced by a moderate correlation between the preference rankings $(\rho=0.73)$. Overall, labeling played an important part in the choices of this class, but not as much as in class 2. Members of this class are more likely to be female, better educated, more knowledgeable about energy technologies, and have a higher environmental attitude.

From this latent class analysis we can conclude that labeling plays an important role in all three classes, but that there are differences in what their effect is. In class 1, respondents only seem to take the label into account in 2012, but not in 2010. Class 2 seems to pay most attention to the labels in both years, which suggests that they rely heavily on heuristic cues. Class 3 respondents base their choice on a combination of attributes and the labels in both years, which suggests that they experience a more elaborate decision-making process [89]. A second notable finding is that in all classes labeling causes a swing towards renewable energy technologies. This could also be observed in the mixed logit model model, but this model shows that this trend does not differ per class. A final interesting observation is that there is again a class (class 2 ) that is more or less indifferent to the topic, with similar characteristics to those of the indifferent classes in the restricted model.

\subsection{Model comparison}

The results of the restricted model and the free model appear similar, but the latter allowed us to assess the effect of labeling. To find out if both models indeed made similar classes, we explored the overlap between the solutions of the two latent class analyses. We did

\begin{tabular}{|c|c|c|c|c|c|c|c|c|c|c|}
\hline & & \multicolumn{9}{|l|}{ Free model } \\
\hline & & \multicolumn{3}{|l|}{ Class 1} & \multicolumn{3}{|l|}{ Class 2} & \multicolumn{3}{|l|}{ Class 3} \\
\hline & & Estimator & Sig. & $N$ & Estimator & Sig. & $N$ & Estimator & Sig. & $N$ \\
\hline Intercept & & Ref & & & -1.07 & $* * *$ & & -2.26 & $* * * *$ & \\
\hline \multirow{6}{*}{ Restricted model } & Unlabeled class 1 & Ref & & 9 & 0.66 & $* * * *$ & 6 & 5.62 & $* * * *$ & 261 \\
\hline & Unlabeled class 2 & Ref & & 479 & -0.88 & & 68 & -1.43 & $* * * *$ & 12 \\
\hline & Unlabeled class 3 & Ref & & 9 & 4.73 & $* * * *$ & 351 & 1.16 & $* * * *$ & 3 \\
\hline & Labeled class 4 & Ref & & 68 & -0.44 & $* * * *$ & 15 & 3.60 & $* * * *$ & 260 \\
\hline & Labeled class 5 & Ref & & 105 & 2.33 & & 371 & -2.40 & & 1 \\
\hline & Labeled class 6 & Ref & & 239 & Ref & & 82 & Ref & & 25 \\
\hline McFadden $R^{2}$ & & 0.55 & & & & & & & & \\
\hline$N$ & & 2364 & & & & & & & & \\
\hline$\chi^{2}$ & & $2789.7^{* * * *}$ & & & & & & & & \\
\hline
\end{tabular}

Table 6

Results of the multinomial regression model, including cross tabulation of class memberships.

$* * * * 0.001$. 
this by conducting a multinomial regression in which membership of the free three-class model was predicted by membership of the restricted six-class model (see Table 6).

The model is highly significant and performed well with a McFadden $R^{2}$ of 0.55 . Both latent class models are strongly related. The unlabeled classes of the restricted model almost have a one-toone relationship with the classes of the free model. The outcome for the labeled classes is more complex. The majority of members in the restricted classes are also members of a specific free class, but there are larger overlaps with the other free classes.

Despite the strong overlap between the models, our results demonstrate that the latent classes in the free model were largely determined by the unlabeled condition. This might be because respondents in the unlabeled classes were less dynamic overall in their preferences over time (except for the indifferent class, but the change in estimators is really small), which made it easier for the model to identify latent classes.

\section{Limitations}

This study suffers from a number of limitations. First, the samples of both DCEs are independent. Although this prevents instrumentation effects, this also makes it impossible to observe individual level changes. These changes could have given insight into why the preference for technologies changed over time. Although the Fukushima incident is a likely cause, the present research design does not exclude rival explanations. However, it is hard to study preference dynamics in the longer term under controlled conditions to exclude possible rival explanations. Researchers may have to resort to longitudinal field data, possibly augmented with qualitative interviews.

A second limitation is that we surveyed only one geographical region, which means that our results cannot be generalized to the entire Dutch population. Our samples were nevertheless quite representative for the province of Utrecht and give valuable indications about how preferences might have changed in other provinces.

A final potential limitation relates to the list of attributes that were included in the choice experiments. These were formulated in such a way that they were applicable to all technologies. The downside is that the attributes may have been too abstract for some respondents. This was partly compensated by the technology names in the label, which left room for inferring additional technology-specific attributes. Future research could consider adding such attributes to the choice task.

\section{Conclusions and implications}

Our discussion of public acceptance shows that the concept is used in diverse and often inconsistent ways. By breaking the concept down into its constituent components, we show that the concept can relate to different types of agents and stages of the innovation process in different studies. Our conceptualization expands upon that of Wüstenhagen et al. [2], by including the different roles that agents can take in different stages of the innovation process as well as how this shapes preference formation.

Our empirical investigation focuses on citizens' socio-political acceptance of energy technologies and further improves our conceptualization of public acceptance by investigating the roles that labels, time, and heterogeneity can play in the formation of preferences. Our results demonstrate that labeling has a profound impact on the stated preferences for energy technologies. In the unlabeled condition of the mixed logit model, nuclear energy, energy from coal with CCS, and biomass energy are most preferred. In the labeled condition offshore wind energy, biomass energy, and energy from gas with CCS score highest. This indicates that labels have a strong influence on the public acceptance of energy technologies and that they elicit stronger preferences for renewable energy technologies. Furthermore, until now it was unclear how time influences the average stated preferences for energy technologies. Our results demonstrate that, in the case of energy technologies, the average preferences remained relatively stable.

This picture becomes more refined when public heterogeneity is taken into account. Here, our restricted model shows that, in the unlabeled condition, there is a specific class that changed its preferences for technologies attributes, whereas in the labeled condition there is a class that changed its preferences about nuclear energy. Thus, in both conditions there is a class that changed preferences, but the reasons were different. In addition, the free model shows that in all classes labeling played a role, but that the extent of influence on preferences differs between classes. This indicates that changes in public acceptance are not population-wide, but are limited to specific sub-groups.

A third insight is that both latent class analyses revealed differences between classes in terms of how strong their preferences were. Some classes revealed a much larger difference between estimators than others. Indifferent respondents are typically male, less educated, less aware of the environment, and have a lower income.

A final insight is that we can characterize preferences for technologies by respondent characteristics. These results are in line with findings by earlier studies $[15,32,75,90,91]$. Women who are better educated and have a high environmental awareness are most in favor of renewable energy technologies (solar energy, both types of wind energy, and biomass energy). Most support for nuclear energy can be found among men who are less educated and have a low environmental awareness (restricted classes 3 and 5), but these groups are also the most indifferent. In almost all classes, support for fossil fuels (coal and natural gas) is low and declines over time. Energy from coal with CCS is more appreciated in the unlabeled condition, whereas energy from gas with CCS is more appreciated in the labeled condition. Both technologies typically end up near the center of the preference rankings.

Overall, we conclude that studies on the public acceptance of energy technologies need to be clear about the type of acceptance they measure as well as the roles played by the involved agents. Next, they should account for the effects of labels, time, and heterogeneity. Otherwise, insights that could be useful from a theoretical and policy perspective may be overlooked.

\subsection{Theoretical implications}

Preferences for energy technologies can be constructed in situations where technology names are observable as well as in situations where they remain hidden. When consumers choose between different electricity providers and the packages they offer, the names of the energy technologies may remain unobserved. In this situation, consumers are forced to construct preferences on the basis of attributes such as price and whether or not the source is sustainable. When, on the other hand, public acceptance needs to be acquired during the planning phase of energy projects, such as the construction of power plants, technology names receive a great deal of exposure-as is typically the case in policy decisions. In the light of the results of this study, preferences constructed in these different settings can be expected to differ. Researchers attempting to measure preferences should consider whether or not to mention technology names in the light of the context of the preference construction process they wish to model.

Second, our results show that it may be worthwhile to study the causes of changes in preferences in future research. A distinction needs to be made between valuing attributes and valuing technologies as a whole. Attribute valuation can change as part of societal trends, such as stronger awareness about the environment. Technology 
valuation is sensitive to these trends, but also to specific incidents relating to the technologies. Future research needs to determine how these two aspects of public acceptance change over time, since they appear to change at a different rate and for different reasons.

A third challenge for future research is how to deal with respondents who seem quite indifferent about the topic in comparison with those who have strong preferences. This raises an ethical question: how should their preferences be accounted for in the public debate? Our research shows that not taking into account the opinion of indifferent people favors renewable energy technologies. However, we do not know if this indifference is caused by insufficient knowledge about the topic, by low involvement, or by some other cause [92]. Future research could focus on establishing the causes of this indifference and identify potential remedies.

\subsection{Policy implications}

Our results indicate that policy-makers should account for the effect of labeling on the public acceptance of energy technologies. The public debate is more than a technocratic discussion about actual attributes and their consequences. It also involves the attributes that people infer from a technology and emotions that are attached to a name. Such factors should be taken seriously if public acceptance is to be obtained.

Second, although incidents relating to a specific technology might influence public acceptance in the short term, our results suggest that the influence of such incidents over the longer term is modest. For policy-makers, this implies that there is no direct need to adjust energy policies as a result of such incidents.

Third, policy-makers and energy companies should not only consider the average valuation of a technology, but should also take public heterogeneity into account in their decision-making process and communication strategy. This is especially advisable when technologies are particularly controversial. For example, our results show that the valuation of solar energy differs between classes in the 2012 labeled condition, which means that the technology is quite controversial. A similar result was found for onshore wind energy.

In this context, policy-makers should also consider how to involve classes that are currently indifferent to the topic. Taking into account the preferences of this class strengthens the democratic character of the public debate. Our results identify this class clearly by its characteristics.

We advise energy companies to pay specific attention to the preferences of citizens and users of energy technologies when developing strategies for technology development and deployment. If a technology is to be successful, market acceptance is not sufficient; socio-political acceptance and community acceptance are also necessary. Citizen do not always prefer low-cost technologies, but take other considerations into account. Adapting company strategies to citizen preferences can help to avoid the problems that may result from a lack of socio-political or community acceptance, such as declining public funding, large scale protests or a discontinuation of test facilities.

Finally, on the basis of this research the most accepted alternative would be offshore wind energy, although people who live near the coast might not share this view. The results demonstrate convincingly that fossil fuel technologies such as energy from coal or natural gas can count on little support as part of the future energy portfolio.

\section{References}

[1] SER. Energieakkoord voor duurzame groei. The Hague, The Netherlands; 2013.

[2] Wustenhagen R, Wolsink M, Burer MJ. Social acceptance of renewable energy innovation: an introduction to the concept. Energy Policy 2007;35:2683-91.

[3] Brunsting S, Upham P, Dütschke E, De Best Waldhober M, Oltra C, Desbarats J, et al. Communicating CCS: applying communications theory to public perceptions of carbon capture and storage. Int J Greenhouse Gas Control 2011;5:1651-62.
[4] Van Alphen K, Voorst QVT, Hekkert MP, Smits REHM. Societal acceptance of carbon capture and storage technologies. Energy Policy 2007;35:4368-80.

[5] Söderholm P, Ek K, Pettersson M. Wind power development in Sweden: globa policies and local obstacles. Renewable Sustainable Energy Rev 2007;11:365-400.

[6] Wolsink M. Wind power implementation: the nature of public attitudes: equity and fairness instead of backyard motives. Renewable Sustainable Energy Rev 2007;11:1188-207.

[7] Ladenburg J, Möller B. Attitude and acceptance of offshore wind farms-the influence of travel time and wind farm attributes. Renewable Sustainable Energy Rev 2011;15:4223-35.

[8] Kraxner F, Yang J, Yamagata Y. Attitudes towards forest, biomass and certification-a case study approach to integrate public opinion in Japan. Bioresour Technol 2009;100:4058-61.

[9] Susaeta A, Alavalapati J, Lal P, Matta JR, Mercer E. Assessing public preferences for forest biomass based energy in the southern United States. Environ Manage 2010;45:697-710.

[10] Labay DG, Kinnear TC. Exploring the consumer decision-process in the adoption of solar-energy systems. J Consum Res 1981;8:271-8.

[11] Yuan X, Zuo J, Ma C. Social acceptance of solar energy technologies in Chinaend users' perspective. Energy Policy 2011;39:1031-6.

[12] Bickerstaff K, Lorenzoni I, Pidgeon NF, Poortinga W, Simmons P. Reframing nuclear power in the UK energy debate: nuclear power, climate change mitigation and radioactive waste. Public Understanding of Science 2008; 17:145-69.

[13] Visschers VHM, Keller C, Siegrist M. Climate change benefits and energy supply benefits as determinants of acceptance of nuclear power stations: investigating an explanatory model. Energy Policy 2011;39:3621-9.

[14] Payne JW, Bettman JR, Schkade DA. Measuring constructed preferences: towards a building code. J Risk Uncertainty 1999;19:243-70.

[15] Bergmann A, Hanley M, Wright R. Valuing the attributes of renewable energy investments. Energy Policy 2006;34:1004-14.

[16] Zoellner J, Schweizer-Ries P, Wemheuer C. Public acceptance of renewable energies: results from case studies in Germany. Energy Policy 2008;36:4136-41.

[17] McGowan F, Sauter R. Public opinion on energy research: a desk study for the research councils. Brighton: University of Sussex; 2005.

[18] Batel S, Devine-Wright P, Tangeland T. Social acceptance of low carbon energy and associated infrastructures: a critical discussion. Energy Policy 2013:58:1-5.

[19] De Bekker-Grob EW, Hol L, Donkers B, Van Dam L, Habbema JDF, Van Leerdam $\mathrm{ME}$, et al. Labeled versus unlabeled discrete choice experiments in health economics: an application to colorectal cancer screening. Value Health 2010;13:315-23.

[20] Hensher DA, Rose JD, Greene WH. Applied choice analysis: a primer. Cambridge: Cambridge University Press; 2005.

[21] Slovic P. Perception of risk. Science 1987;236:280-5.

[22] Slovic P, Finucane ML, Peters E, MacGregor DG. The affect heuristic. Eur J Oper Res 2007;177:1333-52.

[23] Tarigan AKM, Bayer SB. Temporal change analysis of public attitude, knowledge and acceptance of hydrogen vehicles in Greater Stavanger, 2006-2009. Renewable Sustainable Energy Rev 2012;16:5535-44.

[24] Faber A, Frenken K. Models in evolutionary economics and environmenta policy: towards an evolutionary environmental economics. Technol Forecast Soc Change 2009;76:462-70.

[25] Windrum P, Ciarli T, Birchenhall C. Environmental impact, quality, and price: consumer trade-offs and the development of environmentally friendly technologies. Technol Forecast Soc Change 2009;76:552-66.

[26] Ajzen I. Attitudes, personality and behavior. 2nd ed.. Berkshire, England: Chocago Illinois, The Dorsey Press; 2005.

[27] Johnston J. The citizen-consumer hybrid: ideological tensions and the case of Whole Foods Market. Theory Soc 2008;37:229-70.

[28] Lockie S. Responsibility and agency within alternative food networks: assembling the citizen consumer. Agric Hum Values 2009;26:193-201.

[29] Blackwell RD, Miniard PW, Engel JF. Consumer behavior. fort worth. Harcourt College Publishers; 2001.

[30] Van Rijnsoever FJ, Oppewal H. Predicting early adoption of successive video player generations. Technol Forecast Soc Change 2012;79:558-69.

[31] Lippmann W. Public opinion. New York: Harcourt, Brace and Co.; 1922.

[32] Van Rijnsoever FJ, Farla J. Identifying and explaining public preferences for attributes of energy technologies. Renewable Sustainable Energy Rev 2014;31:71-82.

[33] Nahuis R, Boon WPC. The impact of patient advocacy: the case of innovative breast cancer drug reimbursement. Sociol Health Illness 2011;33:1-15.

[34] Brunsting S, Mastop J, Kaiser M, Zimmer R, Shackley S, Mabon L, et al. CCS acceptability: social site characterization and advancing awareness at prospective storage sites in Poland and Scotland. Oil Gas Sci Technol-Revue d'IFP Energies Nouvelles 2014.

[35] Couture T, Gagnon Y. An analysis of feed-in tariff remuneration models: implications for renewable energy investment. Energy Policy 2010;38:955-65.

[36] Bass FM. Comments on A new product growth for model consumer durables. Manage Sci 2004;50:1833-40.

[37] Rogers EM. Diffusion of innovations. 3rd ed.. New York: Free Press; 2003.

[38] Devine-Wright P. Enhancing local distinctiveness fosters public acceptance of tidal energy: a UK case study. Energy Policy 2011;39:83-93.

[39] Devine-Wright P. Beyond NIMBYism: towards an integrated framework for understanding public perceptions of wind energy. Wind Energy 2005;8:125-39. 
[40] Burstein P. The impact of public opinion on public policy: a review and an agenda. Polit Res Q 2003;56:29-40.

[41] Page BI, Shapiro RY. Effects of public opinion on policy. Am Polit Sci Rev 1983;77:175-90.

[42] Bimber B. The internet and political transformation: populism. . Community, and Accelerated Pluralism. Polity; 1998. p. 133-60.

[43] Adams J, Haupt AB, Stoll H. What moves parties? Comp Polit Stud 2009;42:611-39.

[44] Gibbons M. The new production of knowledge: introduction. In: Gibbons M editor. The new production of knowledge. London: Sage; 1994.

[45] Hessels LK, van Lente H. Re-thinking new knowledge production: a literature review and a research agenda. Res Policy 2008;37:740-60.

[46] Van Langenhove L. Make social sciences relevant. Nature 2012;484:442.

[47] Van Rijnsoever FJ. Sociology: the social sciences are already relevant. Nature 2012;485:309.

[48] Nahuis R, van Lente $H$. Where are the politics? Perspectives on democracy and technology Sci Technol Hum Values 2008;33:559-81.

[49] Heiskanen E, Johnson M, Vadovics E. Learning about and involving users in energy saving on the local level. J Cleaner Prod 2013;48:241-9.

[50] Robinson J, Burch S, Talwar S, O’Shea M, Walsh M. Envisioning sustainability: recent progress in the use of participatory backcasting approaches for sustainability research. Technol Forecast Soc Change 2011;78:756-68.

[51] Sharma RH, Awal R. Hydropower development in Nepal. Renewable Sustainable Energy Rev 2013;21:684-93.

[52] Petty RE, Wegener DT. The elaboration likelihood model: current status and controversies. In: Chaiken S, Trope Y, editors. Dual-process theories in social psychology. New York: Guilford Press; 1999. p. 37-72.

[53] Chen S, Chaiken S. The heuristic-systematic model in its broader context. In: Chaiken S, Trope Y, editors. Dual-process theories in Social Psychology. New York: Guilford Press; 1999. p. 73-96.

[54] Maheswaran D, Mackie DM, Chaiken S. Brand name as a heuristic cue: the effects of task importance and expectancy confirmation on consumer judgments. J Consum Psychol 1992;1:317-36.

[55] Van Rijnsoever FJ, Castaldi C. Extending consumer categorization based on innovativeness: intentions and technology clusters in consumer electronics. J Am Soc Inf Sci Technol 2011;62:1604-13.

[56] Morwitz VG, Schmittlein D. Using segmentation to improve sales forecasts based on purchase intent: which "intenders" actually buy? J Mark Res 1992;29:391-405.

[57] Vermunt JK, Magidson J. Latent class cluster analysis. In: Hagenaars JA, McCutcheon AL, editors. Applied latent class analysis. Cambridge: Cambridge University; 2002. p. 89-106.

[58] Devetag MG. From utilities to mental models: a critical survey on decision rules and cognition in consumer choice. Ind Corp Change 1999;8:289-351.

[59] Baltas G, Doyle P. Random utility models in marketing research: a survey. J Bus Res 2001:51:115-25.

[60] Batsell R, Louviere J. Experimental analysis of choice. Mark Lett 1991;2:199-214.

[61] Manski CF. The structure of random utility models. Theory Decis 1977;8:229-54.

[62] McFadden D. Conditional logit analysis of qualitative choice behavior. In: Zarembka P, editor. Frontiers in economics. New York: Academic Press; 1974. p. $105-42$.

[63] Ben-Akiva M, Morikawa T, Shiroishi F. Analysis of the reliability of preference ranking data. J Bus Res 1991;23:253-68.

[64] Beshears J, Choi JJ, Laibson D, Madrian BC. How are preferences revealed? J Public Econ 2008;92:1787-94.

[65] Louviere JJ, Woodworth G. Design and analysis of simulated consumer choice or allocation experiments: an approach based on aggregate data. J Mark Res 1983;20:350-67.

[66] Louviere J, Flynn T, Carson R. Discrete choice experiments are not conjoint analysis. J Choice Model 2010;3:57-72.

[67] Podsakoff PM, MacKenzie SB, Lee JY, Podsakoff NP. Common method biases in behavioral research: a critical review of the literature and recommended remedies. J Appl Psychol 2003;88:879-903.
[68] Van Rijnsoever FJ, Meeus MTH, Donders ART. The effects of economic status and recent experience on innovative behavior under environmental variability: an experimental approach. Res Policy 2012;41:833-47.

[69] Carson RT, Louviere JJ, Anderson DA, Arabie P, Bunch DS, Hensher DA, et al. Experimental analysis of choice. Mark Lett 1994;5:351-67.

[70] Van Rijnsoever FJ, Hagen P, Willems M. Preferences for alternative fuel vehicles by Dutch local governments. Transp Res: Part D: Transport Environ 2013;20:15-20.

[71] Scarpa R, Willis K. Willingness-to-pay for renewable energy: primary and discretionary choice of British households' for micro-generation technologies. Energy Econ 2010;32:129-36.

[72] Kwak S-Y, Yoo S-H, Kwak S-J. Valuing energy-saving measures in residential buildings: a choice experiment study. Energy Policy 2010;38:673-7.

[73] Achtnicht M, Madlener R. Factors influencing German house owners' preferences on energy retrofits. Energy Policy 2014;68:254-63.

[74] Karytsas S, Theodoropoulou H. Public awareness and willingness to adopt ground source heat pumps for domestic heating and cooling. Renewable Sustainable Energy Rev 2014;34:49-57.

[75] Bergmann A, Colombo S, Hanley N. Rural versus urban preferences for renewable energy developments. Ecol Econ 2008;65:616-25.

[76] Shin J, Woo J, Huh S-Y, Lee J, Jeong G. Analyzing public preferences and increasing acceptability for the Renewable Portfolio Standard in Korea. Energy Econ 2014;42:17-26.

[77] Hensher DA, Shore N, Train K. Willingness to pay for residential electricity supply quality and reliability. Appl Energy 2014;115:280-92.

[78] Campbell CJ, Laherrere JH. Preventing the next oil crunch-the end of cheap oil. Sci Am 1998;278:77-83.

[79] Morse EL, Richard J. The battle for energy dominance. Foreign Aff 2002;81 16 - + .

[80] Allen SR, Hammond GP, McManus MC. Prospects for and barriers to domestic micro-generation: a United Kingdom perspective. Appl Eneroy 2008:85:528-44.

[81] Flynn LR, Goldsmith RE. A short, reliable measure of subjective knowledge. J Bus Res 1999;46:57-66.

[82] Dunlap RE, Van Liere KD, Mertig AG, Jones RE. Measuring endorsement of the new ecological paradigm: a revised NEP scale. J Soc Issues 2000;56:425-42.

[83] Swait J, Louviere J. The role of the scale parameter in the estimation and comparison of multinomial logit models. J Mark Res 1993:305-14.

[84] Sælensminde K. Inconsistent choices in Stated Choice data. Transportation 2001;28:269-96.

[85] Magidson J, Vermunt JK. Removing the scale factor confound in multinomial logit choice models to obtain better estimates of preference. In: Sawtooth software conference, 2007, p. 139.

[86] Greene WH, Hensher DA. A latent class model for discrete choice analysis: contrasts with mixed logit. Transp Res: Part B: Methodol 2003;37:681-98.

[87] Nylund KL, Asparouhov T, Muthén BO. Deciding on the number of classes in latent class analysis and growth mixture modeling: a Monte Carlo simulation study. Struct Equ Model 2007;14:535-69.

[88] Schwarz G. Estimating the dimension of a model. Ann Stat 1978;6:461-4.

[89] Petty RE, Cacioppo JT. From communication and persuasion: central and peripheral routes to attitude change. New York: Springer-Verlag; 1986.

[90] Diamantopoulos A, Schlegelmilch BB, Sinkovics RR, Bohlen GM. Can sociodemographics still play a role in profiling green consumers? A review of the evidence and an empirical investigation J Bus Res 2003;56:465-80.

[91] Gilg A, Barr S, Ford N. Green consumption or sustainable lifestyles? Identifying the sustainable consumer Futures 2005;37:481-504.

[92] De Best-Waldhober M, Daamen D, Faaij A. Informed and uninformed public opinions on $\mathrm{CO}_{2}$ capture and storage technologies in the Netherlands. Int J Greenhouse Gas Control 2009;3:322-32.

[93] Walker G, Devine-Wright P, Hunter S, High H, Evans B. Trust and community: exploring the meanings, contexts and dynamics of community renewable energy. Energy Policy 2010;38:2655-63.

[94] Geels FW. From sectoral systems of innovation to socio-technical systems: insights about dynamics and change from sociology and institutional theory. Res Policy 2004;33:897-920. 